\title{
ARTIGO \\ SOCIOEDUCAÇÃO: ENTRE A SANÇÃO E A PROTEÇÃO
}

\author{
VANESSA PETERMANN BONATTO ${ }^{1}$ \\ ORCID: https://orcid.org/0000-0002-2279-7650 \\ DÉBORA CRISTINA FONSECA ${ }^{2}$ \\ ORCID: http://orcid.org/0000-0001-8427-5973
}

\begin{abstract}
RESUMO: O objetivo deste artigo é refletir sobre o sentido da socioeducação e suas contradições na prática do orientador de medidas socioeducativas. Para tanto, parte-se de dados de uma pesquisa qualitativa, que utiliza entrevistas como coleta de dados e a compreensão do papel dos socioeducadores nos Centros de Referência Especializados em Assistência Social (CREAS) de cinco municípios do interior do estado de São Paulo. Evidencia-se, por meio de uma análise crítica, contradições entre o socioeducativo e o punitivo. Considerando a complexidade da prática, entende-se que essa questão se relaciona com um contexto sócio-histórico vigente marcado pela lógica da individualização dos problemas sociais, herança da doutrina da situação irregular, corroborando as indicações da literatura da área. Desta forma, apesar dos avanços no sentido de garantia de direitos, a socioeducação, na perspectiva dos participantes da pesquisa, no cotidiano dos serviços, mostra-se dúbia entre a proteção e a punição. Assim, a partir dos resultados da pesquisa, é possível afirmar que a socioeducação se efetiva na contradição decorrente de sua pouca precisão conceitual, bem como das dificuldades de execução no cotidiano dos serviços. De tal maneira, grande parte das ações socioeducativas acabam sendo mais punitivas. A partir desta percepção, faz-se necessário aperfeiçoamento das políticas públicas, desenvolvimento e participação coletiva na construção e aplicação de uma proposta de socioeducação.
\end{abstract}

Palavras-chave: Socioeducação, Medida socioeducativa, Políticas públicas.

\section{SOCIO-EDUCATION: BETWEEN SANCTION AND PROTECTION}

\begin{abstract}
The objective of this article is to reflect on the sense of socioeducation and its contradictions in the practice of the social education counselor. For that, it analyses data of a qualitative research, which uses interviews and the understanding of the role of socio-educators in the Specialized Reference Centers in Social Assistance (CREAS) of five municipalities in the interior of the state of São Paulo. Through critical analysis, it is evident the contradictions between socio-educational and punitive goals. We understand, considering the complexity of the practice that this issue relates to a current sociohistorical context marked by the logic of the individualization of social problems, an inheritance of the doctrine of the irregular situation that corroborates with the indications of the literature of the area. Thus, despite advances in the direction of guaranteeing rights, socio-education, from the perspective of the

\footnotetext{
${ }^{1}$ Psicóloga, Mestre em Educação pelo Programa de pós graduação em Educação do Instituto de Biociências - Universidade Estadual Paulista Júlio de Mesquita Filho. Rio Claro, SP, Brasil. <vanessapbonatto@hotmail.com >

2 Professora Doutora do Departamento de Educação do Instituto de Biociências - Universidade Estadual Paulista Júlio de Mesquita Filho. Rio Claro, SP, Brasil. < debora.fonseca@unesp.br >
} 
research participants, in the daily life of services, it is dubious between protection and punishment. Thus, from the results of the research, it is possible to affirm that socio-education is effective in the contradiction resulting from its little conceptual precision as well as the difficulties of execution in the daily routine of services. In such a way, most of the socio-educational actions stem from being more punitive. From this perception, it is necessary to improve public policies, development, and collective participation in the construction and application of a proposal for socio-education.

Key words: Socioeducation, Socio-educational measures, Public policies.

\section{SOCIOEDUCACIÓN: ENTRE SANCIÓN Y PROTECIÓN}

RESÚMEN: El objetivo de este artículo es reflexionar sobre el sentido de socioeducación y sus contradicciones en la práctica del consejero de educación social. Para eso, partimos de datos de una investigación cualitativa, que utiliza entrevistas como recopilación de datos y la comprensión del papel de los socioeducadores en los Centros de Referencia Especializados en Asistencia Social (CREAS) de cinco municipios en el interior del estado de São Paulo. Las contradicciones entre lo socioeducativo y lo punitivo se evidencian mediante un análisis crítico. Teniendo en cuenta la complejidad de la práctica, se entiende que este tema está relacionado con un contexto socio-histórico aún prevaleciente marcado por la lógica de la individualización de los problemas sociales, la herencia de la doctrina de la situación irregular, corroborando las indicaciones de la literatura del área. Por lo tanto, a pesar de los avances en términos de garantía de derechos, la educación social, desde la perspectiva de los participantes en la investigación, en la vida diaria de los servicios, es dudosa entre la protección y el castigo. Por lo tanto, a partir de los resultados de la investigación, es posible afirmar que la socioeducación es efectiva en la contradicción resultante de su poca precisión conceptual, así como las dificultades de ejecución en la rutina diaria de los servicios. De tal manera, la mayoría de las acciones socioeducativas terminan siendo más punitivas. De esta percepción, es necesario mejorar las políticas públicas, el desarrollo y la participación colectiva en la construcción y aplicación de una propuesta de educación social.

Palabras clave: Socioeducación, Medida socioeducativa, Políticas públicas.

\section{INTRODUÇÃO}

Com o advento do Estatuto da Criança e do Adolescente (ECA, BRASIL, 1990), o termo socioeducação evidenciou-se. Este aparece em vários documentos relacionados à definição e ao cumprimento das medidas socioeducativas aplicadas aos adolescentes em conflito com a lei, porém sem uma conceituação clara.

No âmbito da temática da Socioeducação e Medidas Socioeducativas em meio aberto, que se relacionam intrinsecamente, o Sistema Nacional de Atendimento Socioeducativo (SINASE), apresentado em 2006 e implementado através da lei nº12.594/2012 (BRASIL, 2012), propõe um melhor delineamento para a superação da tradição assistencial-repressiva no atendimento ao adolescente autor de ato infracional. Tal definição se expressa como "um conjunto ordenado de princípios, regras e critérios, de caráter jurídico, político, pedagógico, financeiro e administrativo, que envolve desde o processo de apuração de ato infracional até a execução da medida socioeducativa" (CONANDA, 2006, p. 151).

Nessa relação, a figura do orientador de medida socioeducativa torna-se de suma importância, dado que é o elo principal entre os adolescentes em conflito com a lei e o sistema socioeducativo. Porém, enfrenta desafios para efetivamente aplicar, conforme a lei, as dimensões socioeducativas, tendo em vista a ambiguidade nas definições sobre essa política, bem como a ausência de equipamentos efetivos para a garantia dos direitos desses jovens. 
No que se refere ao contexto de execução das medidas, de acordo com o Relatório da pesquisa nacional das medidas socioeducativas em meio aberto no Sistema Único de Assistência Social (SUAS, BRASIL, 2018), o país possui 117.207 adolescentes e jovens em cumprimento de Medidas Socioeducativas de Liberdade Assistida (LA) e/ou Prestação de Serviços à Comunidade (PSC). Estas duas medidas concentram $82 \%$ de todas as aplicadas no Brasil; o que nos mostra que os outros $28 \%$ estão distribuídos entre as medidas de semiliberdade e internação. Tais dados são representativos do quanto a execução das medidas de LA e PSC têm se consolidado dentro do SUAS, especialmente nos CREAS, equipamento que a legislação da área estabelece como o lócus exclusivo para esta oferta.

Nesse seguimento, o mesmo relatório demonstra que, dos municípios brasileiros participantes da pesquisa que tem CREAS, ou realizam esse atendimento em outros equipamentos, $90 \%$ atendem o serviço de medidas socioeducativas em meio aberto.

É fundamental, então, ressaltar o caráter de sanção (resposta do Estado a um ato infracional) da execução das medidas, muito embora saibamos que sua efetivação devesse priorizar uma integração entre a dimensão educativa e a consideração das necessidades sociais dos adolescentes em conflito com a lei. Com isso, carece de observação o que está previsto na legislação específica, bem como o protagonismo do CREAS enquanto executor de medidas na socioeducação. Sobre isso, Jacques (2015) expõe:

[...] o Estatuto não pretendeu que as Medidas Socioeducativas tivessem um caráter sancionatório, punitivo e retributivo, no entanto, não podem ter outro significado, pois são a resposta do Estado à prática de ato infracional, assumindo, por isso, o caráter de infração/sanção, a exemplo das penas e não de prêmio (JACQUES, 2015, p. 46).

Nesse contexto, a literatura disponível tem apontado que - apesar do avanço legal no sentido de modificações nas sanções aplicadas aos adolescentes autores de atos infracionais, culminando, nos dias de hoje, com as medidas cujos objetivos ultrapassam a ideia de punição - as orientações técnicas para a aplicação das medidas parecem insuficientes e ambíguas. Considerando seu caráter dúbio (dimensão educativa e sanção) no cotidiano dos serviços, há que se ter em conta fatores que acabam por interferir de diversas maneiras. Estas vão desde as variadas interpretações da concepção de ação socioeducativa, passando pela ausência de políticas públicas que acolham as necessidades desses jovens, até a pouca experiência formativa de muitos orientadores de medidas, causando equívocos sobre suas funções.

Desta forma, a partir do processo de revisão de literatura, percebe-se que prevalece a tendência de realização de pesquisas no âmbito das medidas socioeducativas em meio fechado, aspecto que ressalta a importância da pesquisa da qual esse artigo é fruto. Contudo, há um movimento crescente de interesse na realização de pesquisas sobre a socioeducação em sua especificidade, tais como Miranda (2018), que aborda a intersetorialidade em seus aspectos teóricos e conceituais, e Oliveira (2018), que se dedicou a refletir sobre como as políticas socioeducativas e as medidas socioeducativas em meio aberto têm sido implementadas nos municípios brasileiros.

Nesse movimento, várias pesquisas (VENTURA, 2014; JACQUES, 2015; BEHR, 2016 dentre outros) demonstram que a execução dessas medidas, inclusive em meio aberto, tem apresentado a prevalência de práticas coercitivas e discursos moralizantes que contribuem para reprodução de desigualdades sociais. Além deste fato, os pesquisadores destacam como consequência o fortalecimento da concepção de medida socioeducativa como punição, contraditoriamente ao caráter socioeducativo que é defendido na legislação. Percebe-se essa característica entre os atores envolvidos: adolescentes em conflito com a lei, orientadores de medida e demais.

Levando em conta o caráter compreensivo desse trabalho, emergiram do processo de pesquisa alguns questionamentos: A legislação pode estar contribuindo para a manutenção da lógica da sanção em detrimento de aspectos como o social e o educativo? Quais fatores contribuem para a execução precária da socioeducação? Como superar a lógica da sanção/punição em favor de práticas includentes? Quais as possibilidades de práticas diferenciadas por parte dos orientadores de medidas 
socioeducativas, uma vez que atuam dentro de uma realidade socioeconômica e política de assistência social como a brasileira?

A partir dessas inquietações, esse artigo objetiva refletir sobre o sentido da socioeducação e suas contradições na execução e na prática do orientador de medidas socioeducativas. Tendo em vista a complexidade de fatores e determinações que constituem o objeto de pesquisa e o espaço restrito de um artigo, certos aspectos foram selecionados para análise do sentido conceitual de socioeducação e sua possibilidade concreta para a superação do modelo punitivo, tendo como referência os profissionais que atuam nesse processo.

\section{ASPECTOS TEÓRICOS E METODOLÓGICOS}

Este artigo constitui-se como recorte de uma pesquisa qualitativa de mestrado, realizada na área da educação. Seu objetivo foi compreender a socioeducação e a execução das medidas socioeducativas em meio aberto, com foco de investigação na perspectiva dos socioeducadores que atuam em Centros de Referência Especializados de Assistência Social (CREAS) de cinco municípios do interior paulista.

Foram realizadas entrevistas semiestruturadas (MINAYO, 2009), com oito profissionais orientadores de medida em meio aberto, seguindo todos os cuidados éticos, haja vista a aprovação da pesquisa pelo $\mathrm{CEP}^{3}$. Os dados coletados foram organizados na perspectiva da Análise de Conteúdo, conforme proposto por Bardin (2010). Também foi realizado o estudo documental (MINAYO, 2009) de legislações pertinentes do qual trataremos abaixo.

Segundo a lei $\mathrm{n}^{\circ} 12.435 / 2011$ (BRASIL, 2011), o CREAS é a unidade pública estatal, de abrangência municipal ou regional, que tem como papel constituir-se em lócus de referência nos territórios. Também cuida da oferta de trabalho social especializado no SUAS a famílias e indivíduos em situação de risco pessoal ou social, por violação de direitos. Suas funções no Sistema Único de Assistência Social (SUAS) definem, igualmente, suas atribuições na rede de atendimento. Em suma, executa os serviços de Proteção e Atendimento Especializado a Famílias e Indivíduos (PAEFI) e o Serviço de Proteção Social a Adolescentes em Cumprimento de Medida Socioeducativa de Liberdade Assistida (LA) e de Prestação de Serviços à Comunidade (PSC).

Baseado no SINASE (BRASIL, 2012), há uma composição ideal da equipe de referência do CREAS por profissionais de diversas áreas. Geralmente, os profissionais executores de medida mais presentes são psicólogos e assistentes sociais; entretanto, a depender das condições de constituição de equipe técnica de referência para o Serviço de MSE em Meio Aberto do município, ou ocorrência de equipe incompleta, isso pode se alterar.

Entre os participantes que integraram a pesquisa, dois eram do sexo masculino e seis do sexo feminino. Dentre estes, cinco possuem formação na área da Psicologia e três em Serviço Social. No que concerne ao tempo de formação, os entrevistados têm entre quatro e quinze anos de atuação, com experiências provenientes também de outros locais de trabalho, como em equipamentos da rede intersetorial, na área da saúde e instituições de acolhimento de crianças e adolescentes. O critério para inclusão foi atuar na execução das medidas socioeducativas em meio aberto (Liberdade Assistida e Prestação de Serviços à Comunidade) em CREAS e aceitar participar da pesquisa. Para garantia de sigilo e anonimato, os nomes citados são fictícios.

Em relação à ancoragem teórica e metodológica da pesquisa, bem como desse artigo, empregou-se uma perspectiva crítica e sócio-histórica, à luz do método materialista histórico e dialético discutido por Marx ([1859] 2008), Kosik (1976), Netto (2011) entre outros. Assim, buscou-se realizar uma análise histórica e dialética, sobre a materialidade entre as concepções de socioeducação dos socioeducadores e os pressupostos da socioeducação do Sistema Único de Assistência Social (SUAS) e do Sistema Nacional Socioeducativo (SINASE).

Desta forma, nas seções a seguir, são apresentados os resultados e as reflexões com foco no recorte proposto para este artigo, qual seja a análise do sentido de socioeducação e sua possibilidade

${ }^{3}$ Pesquisa aprovada pelo CEP sob no CAAE: 78550617.7.0000.5465. 
concreta para a superação do modelo punitivo, tendo como referência os profissionais que atuam nesse processo.

Ao avaliarmos a socioeducação em sua historicidade e contexto, identificamos contradições estruturais, produto de um sistema capitalista e neoliberal cujas estratégias e movimentos voltam-se para a formação de sujeitos acríticos. Afirmamos, assim, que na concepção de socioeducação presente nos documentos normativos, a definição operacional e não conceitual permite que práticas punitivas sejam travestidas de socioeducativas. Partindo desse pressuposto, buscamos apreender como os orientadores de medidas socioeducativas compreendem a socioeducação e como significam suas práticas cotidianas.

\section{SOCIOEDUCAÇÃO: FRAGMENTOS CONCEITUAIS E PRÁTICOS}

A socioeducação ocorre em vários contextos, dentre estes, na execução das medidas socioeducativas enquanto respostas do Estado ao ato infracional praticado por adolescentes. Essas respostas do Estado, previstas nos documentos oficiais (ECA, SINASE e outros), devem pautar-se em ações que promovam a ressignificação do projeto de vida e deem oportunidades aos jovens, concomitante com a responsabilização pelos atos praticados, conforme sua gravidade.

Contudo, apesar dos novos fundamentos previstos no ECA, a literatura indica que, ideologicamente, subsistem práticas e representações de criminalização dos adolescentes, acentuadamente enfatizadas pela mídia, relacionando a responsabilização à ideia de punição, herança do periódo histórico anterior ao ECA, ou seja, do Código de Menores. À vista disso, o sentido produzido para o conceito de socioeducação pode ser elencado como um dos problemas criados pelos juristas, ao retirarem os fundamentos epistemológicos da socioeducação e elencarem-na como prática operativolegal.

No levantamento bibliográfico acerca de legislação relativa à socioeducação e medidas socioeducativas, identificou-se a presença do termo nos seguintes dispositivos: a) na lei n $^{\circ} 8.069$ (BRASIL, 1990), que institui o Estatuto da Criança e do Adolescente - ECA; b) na publicação do Conselho Nacional dos Direitos da Criança e do Adolescente, que apresenta o Sistema Nacional de Atendimento Socioeducativo - SINASE (CONANDA, 2006) e c) na lei $\mathrm{n}^{\circ} 12.594 / 2012$ (BRASIL, 2012), que o consolida, uma vez que a execução das medidas socioeducativas no país está sujeita às disposições nelas contidas.

O conceito de socioeducação no Brasil emerge em meados de 1980, com o objetivo de delimitar a proposição do paradigma punitivista, vigente até então, no tocante ao trato do "menor delinquente" conforme indicado por Rizzini, Sposati e Oliveira (2019). Isto é, surge a proposta de superação da prática que pune para um novo paradigma, fundamentado em práticas educativas em oposição à penalização. Segundo discussão de Cunha e Oliveira (2017), a doutrina do direito penal do menor - fruto da lei n5.083, de 1927 - Código de Mello Matos, corrente até a época - cristalizou o binômio carência/delinquência, e a ação estatal caberia àquelas crianças e adolescentes denominadas em "situação irregular" (população pobre, negra, de áreas periféricas, em sua maioria, e que cometiam delitos). Ambas as noções estavam fortemente atreladas à ideia de patologia social. Portanto, havia (há) criminalização da pobreza aliada a práticas assistencialistas com o objetivo de prevenir/coibir uma conduta criminosa por meio da punição.

Com o advento do ECA (BRASIL, 1990), num contexto de redemocratização, crianças e adolescentes em geral passam a ser reconhecidos perante a lei como sujeitos de direitos. Adiante, em 2005, com a aprovação e regulação do Sistema Único de Assistencia Social - SUAS, conforme Moreira, Müller e Cruz (2012), materializa-se a política pública de garantia de direitos e proteção social, provocando uma ruptura com a concepção assistencialista das políticas públicas voltadas aos desvalidos.

Posteriormente, após um longo período de discussões parlamentares e acordos, têm-se a aprovação do SINASE (BRASIL, 2012). Esta seria uma legislação referencial para a operacionalização do atendimento ao adolescente autor de ato infracional, reconhecendo, conforme previsto no ECA, a situação especial de desenvolvimento dos adolescentes. Contudo, esta legislação avança na proposição de uma política de atendimento a esses jovens ao mesmo tempo em que parece não superar 
concretamente a natureza sancionatória. Ou seja, concomitante com as práticas protetivas e socioeducativas, responsabiliza com o cumprimento de medidas restritivas de liberdade, sem criar as condições de efetivação das políticas públicas de acolhimento às necessidades integrais desses jovens.

Enfatizando essa discussão, Rizzini, Sposati e Oliveira (2019), Machado (2016) e Gelli (2013), apontam Costa (2006), jurista que contribuiu para a construção das políticas socioeducativas, como pioneiro em procurar uma resposta conciliatória à problemática epistemológica da necessidade de ação do Estado em face do cometimento do ato infracional por crianças e adolescentes. $\mathrm{O}$ caminho encontrado foi aliar responsabilização e proteção social, apresentando uma concepção de socioeducação subordinada a "desenvolver o potencial de ser e conviver, prepará-lo [o adolescente] para relacionar-se consigo mesmo e com os outros sem quebrar as normas de convívio social tipificadas na Lei Penal como crime e contravenção" (COSTA, 2006, p.449, grifo nosso). Assim, as medidas socioeducativas enquanto reação punitiva da sociedade diante de uma contravenção penal cometida por um adolescente - deverão, todavia, primar pela preparação e educação do jovem para o convívio social.

Sem dúvida, trata-se de uma questão complexa, principalmente em uma sociedade capitalista, a qual compreende a responsabilidade como um fenômeno individual e não como construção social e histórica em constante movimento.

Nessa perspectiva, Kosic (1976), enfatiza a ideia de complementariedade entre todo e partes, de movimento dos fenômenos, destacando que uma compreensão dialética da totalidade, que pode ser concebida como - unidade concreta de forças opostas em uma luta recíproca - significa entender esta não como um todo já pronto e que determina seu conteúdo ou partes, mas que, ao contrário, se constitui das partes ao passo que o inter-relacionamento entre elas o constitui, sendo estas relações nunca estáticas, portanto complexas.

Diante disso, nesse modelo de sociedade capitalista, o conceito de socioeducação necessariamente só faz sentido ao abarcar a responsabilização individual como reparação às violações de convivência social previstas na lei.

Desta forma, a medida socioeducativa, na qualidade de meio para concretização da socioeducação, tem finalidade pedagógica, buscando a ressocialização do adolescente/jovem por meio de ações educativas. Conforme consta já no primeiro capítulo do SINASE, "Marco Situacional":

\footnotetext{
A mudança de paradigma e a consolidação do Estatuto da Criança e do Adolescente (ECA) ampliaram o compromisso e a responsabilidade do Estado e da Sociedade Civil por soluções eficientes, eficazes e efetivas para o sistema socioeducativo e asseguram aos adolescentes que infracionaram oportunidade de desenvolvimento e uma autêntica experiência de reconstrução de seu projeto de vida (BRASIL, 2012, p. 160).
}

Não obstante, em diferentes trabalhos, se observa a constatação de carência nas definições específicas a respeito da natureza sociopedagógica nas legislações normativas, aspecto que também foi identificado na pesquisa que é base desse artigo.

Por esse ângulo, faz-se relevante considerar que, conforme Teixeira (2015) e Raniere (2014) houve a mudança do termo socioeducação sem alterar, no entanto, os pressupostos conceituais, permanecendo a essência da responsabilização individual (por vezes, punitiva) já prevista no Código de Menores. Nesse sentido, mantém traços de imediatismo e uma certa tendência a empreender mudanças apenas no campo semântico ou jurídico sem, contudo, implicar mudança de realidade mais ampla e complexa.

Passados quase trinta anos de aprovação do ECA, muitas reflexões sobre as medidas socioeducativas se desenvolveram e avanços nas formas de entendimento podem permitir outras práticas. Nesse seguimento, questionou-se: Qual compreensão os profissionais que executam as medidas têm sobre socioeducação? $\mathrm{O}$ que seria sociopedagógico no cotidiano da execução das medidas socioeducativas em meio aberto, na vivência dos operadores diretos da política de atendimento no que se refere ao cumprimento das medidas aplicadas?

De forma geral, o que se constatou nas entrevistas foi a dificuldade de diferenciação entre medidas protetivas e socioeducativas; sendo que as socioeducativas, para eles, se concretizam, por vezes, 
meramente como cumprimento de determinação judicial sancionatória, como demonstrado nas falas de Rosário, suplantando a dimensão educativa da medida (ação formadora integrada para a vida em liberdade).

O objetivo é regenerar o adolescente para a sociedade. É um conjunto de medidas determinadas pelo juiz. Nós somos só os executores da medida, o que nos chega do juiz, nós cumprimos (ROSÁRIO).

O sistema de justiça juvenil brasileiro, nas configurações atuais, tem um duplo caráter sancionatório, na aplicação da medida como forma de responsabilização punitiva do adolescente pela violação ao pacto social; e pedagógico, na proposta do atendimento que deveria basear-se em um projeto político-pedagógico voltado a contribuir com o seu desenvolvimento como pessoa e cidadão. São lógicas contraditórias que convivem na Socioeducação, cuja ênfase aos aspectos punitivos se mostram antinômicos ao espírito democrático do ECA (CUNHA; OLIVEIRA, 2017, p.114).

Tendo em consideração estes fatores, a socioeducação parece-nos apresentar limitações à sua efetivação, sendo entendida pelos profissionais como uma ação com resultados positivos, no sentido de ressignificar a trajetória infracional e de vida dos adolescentes. Porém, tal ressignificação ocorre em poucos casos, o que parece indicar o baixo alcance das ações socioeducativas e seus objetivos primordiais, por mais esforços que se empreguem, como ilustram alguns trechos de falas dos entrevistados:

A gente dá um vislumbre aqui. Mesmo quando o jovem sente e diz que não quer cumprir a medida, se ele frequenta um curso que a gente consegue, já é um passo. Se ele vem aqui e consegue falar de algum problema, já é passo também (DOUGLAS).

Em nossa perspectiva teórica, só é possível compreender os fenômenos em sua complexidade, em totalidade dialética, histórica e concreta, em um movimento de constituição do particular e não do individual (NETTO, 2011). Ao buscarmos historicamente a compreensão, observamos que os sentidos construídos pelos profissionais indicam que a socioeducação se concretiza de forma fragmentada em relação ao previsto em lei. Disto, provém a confusão no momento em que se tenta diferenciar medidas socioeducativas e protetivas daquilo que prevalece enquanto compreensão e ênfase (por vezes, indireta) na dimensão de responsabilização (sanção) da medida. A fala de Mariana pode representar como se realizam estes objetivos das medidas socioeducativas nos CREAS:

Faz parte você olhar esse todo, esse social, o indivíduo, o diferencial da medida é que ela vem com um formato de responsabilização pro adolescente, que ai ele vem num formato em que ele é responsabilizado por algo que ele cometeu. Então, tem a socioeducação, e, pensando na medida, acho que essa se encaixa na questão da responsabilização né, do cumprimento (MARIANA).

Contudo, faz-se relevante considerar como fator que contribui para a manutenção da lógica punitivista, de acordo com Rizzini, Sposati e Oliveira (2019), o movimento histórico e social de judicialização do processo socioeducativo nas medidas em meio aberto. Ainda segundo os autores, este movimento é marcado pela desvalorização do conhecimento dos orientadores de medida, que devem cumprir prazos legais, independente do histórico de aproximação e de vínculos construídos com os adolescentes. O mesmo se pode dizer sobre o estabelecimento de metas fixas, por autoridade judicial competente, a serem cumpridas e que funcionam como indicativo da ressocialização ou não do adolescente.

Nesse processo, supõe-se um padrão de intervenção generalista, que não abarca as condições do município e território em que o adolescente está inserido (e para o qual irá retornar). Ou seja, ignoramse as oportunidades de acesso que este tem ou não, as condições concretas de vida, e de formação do particular. Portanto, nega-se a constituição de cada sujeito em suas condições históricas e concretas (MARX[1859] 2008), o que acaba contraditoriamente por arraigar a desproteção desse adolescente. 
Dessa maneira, evidencia-se também o processo histórico demarcado pela contradição da realidade gestada pela luta entre os distintos projetos de sociedade em que socioeducadores e adolescentes em conflito com a lei se relacionam.

Esses fragmentos conceituais esvaziados de sentido ressaltam as incongruências na execução das medidas; ainda que os orientadores possam ter a intencionalidade socioeducativa, ela não se realiza pelos diferentes elementos que atravessam essa realidade, inclusive pelo modo como os próprios adolescentes interpretam as medidas, qual seja, de punição, como se evidencia em diferentes estudos como Cardoso (2017), Carvalho (2018), entre outros.

\section{MEDIDAS SOCIOEDUCATIVAS, PRÁTICAS CONCEBIDAS E EXECUTADAS}

A pesquisa buscou se aproximar das práticas dos orientadores de medidas em meio aberto a fim de refletir sobre as relações e implicações que o sentido de socioeducação impõe a estas no cotidiano do atendimento dos adolescentes autores de atos infracionais. Para tanto, procurou-se apreender como são desenvolvidas as ações socioeducativas previstas em lei no contexto da medida socioeducativa em meio aberto em CREAS.

Nesse sentido, refletir sobre as medidas socioeducativas e suas contradições, especialmente as em meio aberto, dialogando com a compreensão destas para aqueles que as executam, implica considerar que os espaços de aplicação das medidas (aberto e fechado) são diversos (pelo modo como estabelecem suas ações) e potentes em suas possibilidades socioeducativas ou punitivas.

Movimento que pode ilustrar o pressuposto metodológico materialista histórico e dialético, qual seja, da necessidade de ir além de explicar as contradições, mas reconhecê-las, em uma base objetiva real com aspectos cambiantes e antagônicos, de acordo com Marx (1989).

Por este ângulo, a partir dos escritos de Marx ([1859] 2008), esclarecidos por Sawaia (2005), ressalta-se no contexto desse estudo, a importância da particularidade, das mediações que explicam os mecanismos que interferem decisivamente nos modos de ser, uma vez que através dela, da relação que o indivíduo (orientadores de medida) tem com a sociedade (Socioeducação) se concretiza na singularidade (nas práticas nos CREAS).

As medidas socioeducativas em meio fechado são colocadas na lei, no ECA e no SINASE como excepcionais, devendo-se privilegiar o meio aberto (Liberdade Assistida - LA e Prestação de Serviços à Comunidade - PSC), pautando-se na superação da cultura da institucionalização no cuidado com o adolescente em conflito com a lei. Ancora-se na compreensão de que LA e PSC foram concebidas de maneira mais afinada e eficaz na concretização da proposta de ressocialização e construção de projetos de vida que rompam com a trajetória infracional, uma vez que integram em rede os mais diversos serviços públicos e instituições relacionados à proteção e garantia de direitos. Desta forma, é indicada a preferência de aplicação destas medidas.

Entretanto, Teixeira (2015) argumenta que, com a municipalização das práticas de atendimento nas medidas socioeducativas de LA e PSC - enquanto cabe à esfera estadual a apuração e julgamento dos atos e atribuição da aplicação, estruturação e organização das medidas de internação -, consagraram-se estratégias para controle social da juventude e incentivo a parcerias público-privadas, movimentos que se alinham com a lógica neoliberal vigente de redução da responsabilidade direta do Estado e individualização da responsabilidade dos adolescentes e suas famílias.

Neste contraditório, operam políticas públicas buscando a superação da dinâmica da punição e alinhamento com as dimensões educativas e de direitos humanos, com o fortalecimento do protagonismo e promoção de cidadania, como é possível perceber pela fala de Valéria, abaixo. Entretanto, por outro lado, pelo discurso da proteção, se instituem práticas de controle social e intervenção sobre a rotina e o tempo disponível dos adolescentes que este

jam em situação de risco, mesmo que por seis meses, estratégia funcional para esse sistema, como será discutido nessa seção. 
De uma maneira geral é ir lutando pelos direitos daquele que chega aqui, porque muitas, aliás, quase todas as vezes eles têm muito mais direitos violados do que violaram os direitos dos outros. Isso é socioeducação para mim (VALÉRIA).

Majoritariamente, os participantes da pesquisa, quando questionados sobre o significado das medidas socioeducativas, têm suas respostas afinadas com a literatura da área. Isto é, consideram ou citam a ressocialização, bem como a integração social como objetivos fundamentais da medida socioeducativa, nas quais, conforme o SINASE (BRASIL, 2012), as bases pedagógicas devam prevalecer sobre a sanção:

Pelo que eu leio no SINASE e no manual sobre MSE, foi um termo utilizado para substituir a sanção, a punição, que é do código penal, portanto para adultos. O objetivo é ressocializar (SAMUEL).

Nessa perspectiva, a socioeducação e as medidas socioeducativas são compreendidas pelos socioeducadores como fortemente relacionadas à ressocialização:

Oras, é a tentativa de reabilitação de um sujeito, marginalizado pela política pública, e pela cultura
e sociedade, negando-se direitos e por conta dessa negativa de direitos, eles entram em conflito
com a própria cultura. Se ele não é inserido, é obvio que ele vai entrar em conflito (risos). A
medida é a tentativa de reassegurar e reabilitar os direitos perdidos, de forma a tentar reinseri-lo
de forma digna nessa cultura que o colocou pra fora (DOUGLAS).

Mas, qual a compreensão de ressocialização? Quais relações e implicações estabelece na prática? O que se entende por "regenerar o adolescente para a sociedade"?

A implementação do SINASE objetiva primordialmente o desenvolvimento de uma ação socioeducativa sustentada nos princípios dos direitos humanos. Defende, ainda, a ideia dos alinhamentos conceitual, estratégico e operacional, estruturada, principalmente, em bases éticas e pedagógicas (BRASIL, 2012, p. 159).

Os trechos citados parecem indicar uma tendência de ações voltadas à adaptação dos adolescentes em conflito com a lei à dinâmica de funcionamento da vida social. Tal adaptação se daria através do bom comportamento e assimilação das regras sociais em detrimento do oferecimento de (poucas) oportunidades e incentivo ao desenvolvimento de um processo formativo político-crítico. Trata de direitos humanos, quando, no Brasil, esse ainda é um entendimento pouco claro e carregado de estereótipos e preconceitos.

Deste modo, para compreender esse movimento que ocorre no cotidiano dos serviços, de neutralizar o conflito sujeito-sociedade, é preciso, como aponta Netto (2011), uma análise crítica e sóciohistórica de cada um dos complexos constitutivos dessas totalidades, desvelando rigorosamente as tendências que operam especificamente em cada uma delas, processo que demanda captação das transições, do desenvolvimento, da ligação interna e necessária das partes no todo, do processo em sua complexidade, de modo a superar uma visão estagnada e determinista da realidade.

Relacionando esse dado com o Levantamento Anual dos/as Adolescentes em cumprimento de Medida Socioeducativa (BRASIL, 2013, p.44 - 45) sobre as ações e atividades realizadas pelos profissionais no âmbito da Liberdade Assistida, encontramos como atividades comuns: Atendimento individual do adolescente - 98,5\%; Atendimento do adolescente em grupos - 59,1\%; Atendimento com grupos de famílias do adolescente em cumprimento de Liberdade Assistida (LA) 49,8\%; Visita domiciliar - 96,7\%. Atividades estas que também são aplicadas nos CREAS pesquisados.

Contudo, prevalece - especialmente no âmbito da Liberdade Assistida - a aplicação majoritária de técnicas com foco no indivíduo. Portanto, a execução das medidas tem como princípio a responsabilização individual pelo ato e pela ressocialização. Essas práticas parecem permeadas ou mobilizadas por entendimentos dos profissionais, bem como pelas condições concretas dos serviços, em termos de espaços e de oferta de atividades/programas, como exemplificado por Douglas. 
Ah, acho que a estrutura da máquina (em referência ao Estado) limita a gente. Por exemplo, a PSC, a gente tem muita dificuldade de inserir o adolescente em uma atividade. As pessoas em geral não topam, as instituições não os querem lá (DOUGLAS).

Desse modo, o sentido de socioeducação acaba por ser individualizado pela ausência de investimento e garantia de políticas públicas que, de fato, permitam aos orientadores de medidas acolher os jovens em uma perspectiva mais formativa e emancipatória. Simultaneamente, essas práticas também dependem de formação dos profissionais envolvidos, o que, geralmente, é escasso nos serviços socioassistenciais.

Recentemente participei de uma reunião na DRADS, em (Município de referência), mas a prefeitura não oferece nenhuma capacitação. Não há um interesse por parte desse governo de investir nessa área social. Desde 2011, que o CREAS foi implementado, não há valorização desse espaço (SAMUEL).

À vista disso, considerando os conhecimentos das áreas de formação dos participantes, via de regra, conforme indicado por Botelho (2012), os profissionais da Psicologia, bem como Serviço Social, atuam por meio de atendimentos individuais e em grupos. Realizam o levantamento do perfil socioeconômico e familiar dos adolescentes mediante atendimentos individuais e visitas domiciliares, sendo que, a partir destas, começam a ser traçados os perfis e diagnósticos de vulnerabilidade e possíveis riscos sociais, assim como a elaboração do Plano Individual de Atendimento (PIA). Elaboram também relatórios sobre o adolescente e seu processo quando solicitados pelo Juizado da Infância e da Juventude, Promotoria da Infância e da Juventude e/ou Coordenação das Medidas Socioeducativas em Meio Aberto.

Nesse seguimento, cabe destaque para o caráter dialético das práticas socioeducativas: ao mesmo tempo em que garantem direitos sociais negados até então a essa população, fundamentais em nosso sistema, atuam como mecanismos de sanção e controle.

[...] Pelo ECA, nós orientamos que eles são obrigados a estar na escola, que é um direito, mesmo que não queiram (ROSÁRIO).

Por este ângulo, torna-se possível compreender, por meio de uma análise dialética, fundamentada em Marx ([1859] 2008) e exemplificada por Netto (2011), as ações e práticas dos orientadores de medida na sua complexidade e múltiplas determinações, evitando a culpabilização desses profissionais, não obstante sua responsabilidade no processo de constituição e execução das medidas, que se enquadram no modelo neoliberal, sem questionamento das estruturas, todavia, correspondente às expectativa de enquadramento do jovem ao modelo social e sociojurídico.

Nas análises exploratórias da produção de conhecimentos para a política de atendimento socioeducativo, Cunha (2013) demonstra o risco de que as práticas na área apresentem princípios conservadores e renovadores conjuntamente, reproduzindo, assim, o preconceito e a estigmatização, impulsionados pela criminalização da pobreza daqueles que não estão sendo alcançados pelas políticas públicas ou as acessam por via do cometimento de atos infracionais, corroborando a pesquisa de Ávila (2017).

A gente sempre percebe que a educação está bem falha, né, pra ele aí seguir um curso profissionalizante, às vezes eles não acompanham por falta do ensino, e também porque ficam sozinhos e aí não têm a educação no sentido de família, de estrutura [...] eu acho que ele não tem uma educação no sentido de convívio em sociedade, de limites, um sentido pra ele regras de educação, de limites e muitas vezes acho que na escola, nessa parte pedagógica da educação, é muito falha, porque os nossos adolescentes aqui eles estão bem atrasados no sentido de escolarização (IVONE).

Fundamentado nessas reflexões, observa-se que tais posicionamentos conservadores, ainda presentes na atuação, ocorrem por meio de ideologias tanto assistencialistas quanto punitivas. Ambas se entrelaçam à doutrina da proteção integral; por seu turno, apresentam impacto momentâneo, porém enquanto instrumento de transformação, pouco se concretiza. 
Aprofundando as reflexões sobre o termo socioeducacão e a aplicação das medidas socioeducativas, no SINASE (BRASIL, 2012) e no ECA (BRASIL, 1990), nota-se que não há uma definição clara, já que o primeiro aparece diluído indiretamente na conceituação do segundo (medidas socioeducativas), o que resulta, por vezes, em enganos. Complexificando a situação, a ambiguidade ou carência de uma definição mais precisa pode acarretar múltiplas interpretações, eventualmente contraditórias.

\begin{abstract}
Via de regra, eles não querem cumprir. Veja, porque eles são obrigados a fazer algo por isso não querem, a maioria diz isso para mim. Ninguém gosta. Entretanto, isso foi imputado assim como foi imputado o meu trabalho. E eles não querem fazer, é esperado já. Eles dificilmente veem uma medida socioeducativa como uma coisa positiva, uma proteção. Também não acho que é, porque você colocar que trabalhar, prestar serviço é medida protetiva, não é verdade, porque os filhos da elite não são obrigados a isso. Se fosse uma potencialidade de fato, os filhos deles também fariam. Seriam colocados a trabalhar em determinados setores, porque isso os desenvolve. Sabemos que não é bem assim, né (DOUGLAS).
\end{abstract}

O trecho da fala de Douglas nos apresenta uma contradição do sistema socioeducativo se concretizando como uma confusão entre medidas socioeducativas e protetivas, que possuem diferenças, conforme previstas no ECA (BRASIL, 1990). Não se pode desconsiderar que, na aplicação das medidas socioeducativas, também são aplicadas medidas protetivas, e que estas são cumulativas. Sabe-se que, por exemplo, a matrícula na escola não é uma medida socioeducativa, mas sim protetiva, referindo-se ao direito à educação. Porém, essa contradição do sistema socioeducativo contribui para que os adolescentes não a entendam como pertencente à esfera da garantia de direitos e, na outra mão, os profissionais não enxergam como proteção.

Entretanto, Douglas parece se aproximar dessa contradição e de uma compreensão crítica do caráter das medidas ao nos apresentar relevante aspecto, ressaltando a disparidade da aplicação das medidas em relação ao lugar social.

Foi possível apreender, corroborando as colocações de Rizzini, Sposati e Oliveira (2019), que tanto o ECA como o SINASE, especificamente, não indicaram com objetividade como desenvolver as ações socioeducativas ou o que seria a ressocialização, observando-se os diversos e complexos contextos territoriais do país.

Considerando o contexto municipal como relevante na execução das medidas, evidencia-se como ponto comum entre os municípios citados pelos participantes a carência de equipamentos e possibilidades de acesso ao lazer, à cultura e ao esporte. Estes orientadores de medida socioeducativa relatam como causa da carência o desinteresse das gestões municipais em investir nessas áreas. Em dois dos 5 municípios, é indicada a insuficiência dos equipamentos, que geograficamente ficam centralizados, o que dificulta o acesso e permanência nos cursos, por exemplo, por adolescentes de regiões periféricas.

Guardadas as particularidades de cada município, essa questão coaduna com dois relevantes trabalhos. Souza (2018) indica que há falta de programas e projetos que contemplem especificamente a realidade dos adolescentes em conflito com a lei; já Moreira, Müller e Cruz (2012) evidenciam a precariedade da comunicação e relacionamento entre os equipamentos da rede intersetorial no atendimento e enfrentamento das desigualdades sociais, fatores que nos apontam a fragilidade da rede no empenho ao cumprimento do SINASE.

Em rede, a gente tem o preconceito. Quando eu falo pra uma escola que é um menino de medida ninguém quer, entendeu, aí tem que fazer um ofício falando que é obrigação, colocar o promotor no meio pra eles liberarem a vaga. Os meninos não são fáceis, isso é fato, eles dão trabalho mesmo, a maioria tem dificuldade de aprendizagem e a escola, qualquer probleminha eles já expulsam e não quer saber, não tem um acolhimento da escola. É o primeiro passo que a gente tem dificuldade. CAPS não funciona direito, o acolhimento, não tem a busca ativa. Então, falta auxilio da rede (NÁDIA).

Relacionando esse conteúdo, trazido por Nádia, ao da disparidade de acesso à educação e aos dados fornecidos pelo Atlas da Exclusão Social no Brasil - Dez anos depois (GUERRA; 
POCHMANN; SILVA, 2014), podemos inferir certa dinâmica entre escolaridade e investimentos. Observou-se, referente à escolaridade e à alfabetização, baixos índices de escolaridade nos municípios pesquisados (entre 0,53 e 0,61 ) em relação à alfabetização $(0,90$ a 0,92$)$, o que pode ser indicativo de maiores investimentos nos primeiros anos escolares, diminuindo conforme a escolaridade aumenta. A fala de Rosário, abaixo, ilustra essa problemática da escolarização deficitária no processo de cumprimento da medida, ressaltando a potência que a escola tem como espaço de proteção e garantia de direitos quando bem articulada à rede, como indicado por Samuel:

Bom, precisa de mais ofertas de atividades atrativas, de cultura, esporte e lazer no município. A Escola precisa aceitar, cuidar desses jovens também, porque esses meninos sofrem muito com a defasagem, com o preconceito que todos na escola têm para com eles, a escola nega a vaga, de forma que eu preciso brigar para conseguir garantir a vaga, e sem a escola é muito difícil ressocializar, ela é fundamental, porque é lá que eles deveriam estar, ela deveria ser mais atrativa também para protegê-los do crime (ROSÁRIO).

Quando a gente consegue englobar toda a rede para atuar, aí consegue-se os resultados. Percebo que quando há falha na rede, há reincidência do adolescente. Se considerarmos a ressocialização como oportunidade, acredito que podemos entender esse movimento de não se envolver no crime e nossa atividade no CREAS e em rede como ressocialização (SAMUEL).

Entendemos que há outros fatores relacionados à incidência no envolvimento com o ato infracional. Dentre eles, pode-se considerar a evasão escolar, como já constatado por Bazon, Silva e Ferrari (2013) e Cardoso (2017), ao indicarem que esta ocorre a partir do $6^{\circ}$ ano e atinge índice mais alto no ensino médio. Os autores entendem que, especificamente em relação às trajetórias escolares de adolescentes autores de atos infracionais, a frequência escolar de adolescentes e jovens é maior nos anos iniciais escolares. Nesse sentido,

A evasão escolar é tida como um dos grandes fatores que favorecem não só o cometimento de ato infracional, mas a vitimização dos nossos adolescentes em razão da violência urbana instalada (CARVALHO, 2018, p. 59).

Diante desse quadro, guardados os diferentes níveis de acessibilidade territorial aos serviços públicos e características peculiares de cada território em relação à violência presente, entendemos, corroborando Rizzini, Sposati e Oliveira (2019), que há um movimento midiático de exposição exagerada da violência nesses espaços (como escola e sociedade, por exemplo) em relação ao protagonismo dos adolescentes. Tal exposição, aliada às dificuldades encontradas nos serviços, contribui para a demanda atual cada vez mais incidente de medidas restritivas de liberdade, que só promovem o reforço do estigma e a segregação de uma população específica.

Assim, o que se observa é que a educação se concretiza no cotidiano dos serviços com o sentido de uma medida socioeducativa, não como estando na esfera da garantia de direitos. Portanto, o olhar do adolescente está voltado ao caráter de obrigação - em que cabe apenas cumprir -, e não a um exercício de busca e compreensão deste direito, com o auxílio do orientador, sobre a importância da educação em si como formação do sujeito, numa perspectiva de mudança de realidade e de superação das desigualdades, consequentemente, da condição de infrator a que está rotulado.

Considera-se, por isso, que esses fatores interferem sensivelmente no modo como se dão as medidas socioeducativas, e contribuem para limitar a prática e possibilidades de atividades que possam ser oferecidas àqueles que estão em cumprimento de uma medida, principalmente no que concerne à ressignificação das trajetórias de vida e a evitar a reincidência no meio infracional.

\section{CONSIDERAÇÕES FINAIS}

Em síntese, podemos indicar que os resultados da pesquisa evidenciam um processo contraditório entre o legalmente previsto e a prática executiva do sistema socioeducativo. Porém, em uma perspectiva materialista, histórica e dialética, foi possível compreender que há inúmeros fatores - 
dentre eles os diferentes indivíduos envolvidos, o contexto político, econômico, social e histórico, bem como dos municípios - que atravessam o conceito de socioeducação e sua execução nos CREAS.

Não obstante, o conceito de socioeducação parece-nos, e aos que a aplicam, nebuloso em sua constituição de educação em contraposição à punição, no sentido de que deve fundamentalmente contribuir para o desenvolvimento enquanto cidadão do adolescente em conflito com a lei, embora se consolide, em seus elementos pedagógicos, nas medidas socioeducativas que possuem uma natureza sancionatória.

Em relação a marcos políticos e sociais, é notável o avanço representado pelo ECA e SINASE, em conformidade à promoção e garantia de direitos humanos. Entretanto, há indicação da reprodução das desigualdades sociais e produção dos excluídos em parte pelo Estado, Sociedade, Família e instituições sociais, considerando que a dificuldade de articulação e trabalho em rede é citada por vários participantes e pela literatura, o que evidencia a hegemonia de um modelo social que atravessa o cotidiano desses serviços e a vida dos jovens.

Isto posto, pertinente se faz considerar a constituição histórica recente de implementação das políticas públicas na área da socioeducação a partir do ECA, em 1990, e do SINASE, que foi instituído enquanto lei em janeiro de 2012. Ambos nascem em um contexto de resistência, com a elaboração de uma lei que rompesse com o caráter punitivista, ou minimamente atenuasse essa característica das políticas públicas até então. Essa questão nos indica que ocorreu mudanças nos atos normativos sem a devida correspondência com o reordenamento das instituições e práticas, de maneira que uma de suas formas de concretização, as medidas socioeducativas em meio aberto, tem o conceito fortemente relacionado à ressocialização e regeneração desse adolescente infrator, termos relacionados a práticas históricas de seletividade penal.

Como se pode constatar, encontrou-se nos CREAS tendências a ações voltadas à adaptação do jovem à vida social através do bom comportamento (sanção) em detrimento do oferecimento de (poucas) oportunidades de incentivo ao desenvolvimento de processo formativo crítico, a prevalência (por vezes, indireta) de culpabilização da família e a percepção das M.S.E como "casos de polícia" ou "assistencialismo". Todos estes fatores se juntam à reprodução de estratégias e ações que privilegiam atendimentos individuais, em detrimento das coletivas. Desta forma, tem como implicação a reatualização das práticas históricas de punição e segregação combinadas às protetivas. Porém, apesar dos desafios e limitações para as ações, diante de um cenário mais amplo e complexo da execução das medidas, há registros de práticas que potencialmente buscam fortalecer os aspectos protetivos da lei e de garantia da dignidade dos adolescentes e seu desenvolvimento para superação de histórico de direitos violados e do ato infracional.

Buscando contribuir para a produção de conhecimento na área, compreende-se que a problemática maior não se encontra na questão da contradição e ambiguidade inerente à socioeducação (uma vez que, em uma perspectiva dialética, sanção e educação se relacionam constitutivamente em complexidade, de forma que não seja possível sobrepujar uma em detrimento da outra, apesar de suas especificidades), mas sim na apropriação que se faz da questão, transformando e restringindo as medidas socioeducativas (extensão da socioeducação) em formas exemplares de punição. Em outras palavras, em formas de realização de uma inclusão perversa de população específica a que se destina essa ação tida como de justiça justa, ou não, aspecto que ressalta a complexidade e ambiguidade relacionada à alcunha do termo e às contradições das práticas socioeducativas decorrentes.

\section{REFERÊNCIAS}

ÁVILA, Lisélen de Freitas. Assistencialização da Socioeducação: Novas Roupagens para um velho fenômeno. 2017. 108 f. Tese (Doutorado em Serviço Social). - Escola de Humanidades, Pontifícia Universidade Católica do Rio Grande do Sul, Porto Alegre, 2017. Disponível em: http://tede2.pucrs.br/tede2/bitstream/tede/7292/2/Lis\%C3\%A9len $\% 20$ de $\% 20$ Freitas $\% 20 \%$ C3\%81 vila\%20-\%20Tese.pdf. Acesso em: 17 set. 2019. 
BARDIN, Laurence. Análise de conteúdo. Lisboa, Portugal: Edições 70, Lda., 2010.

BAZON, Marina Rezende; SILVA, Jorge Luiz da; FERRARI, Renata Martins. Trajetórias escolares de adolescentes em conflito com a lei. Educação em Revista, [s.l.], v. 29, n. 2, p.175-199, jun. 2013. FapUNIFESP (SciELO). Disponível em: http://www.scielo.br/pdf/edur/v29n2/08.pdf. Acesso em: 17 set. 2019.

BEHR, Mariana Torres. Ressignificando o papel do educador no contexto das medidas socioeducativas. 2016. 150 f. Dissertação (Mestrado em Educação). - Universidade de Brasília, Brasília, 2016. Disponível em: http://repositorio.unb.br/bitstream/10482/22957/1/2016_MarianaTorresBehr.pdf. Acesso em: 17 set. 2019.

BOTELHO, Dayana Aguiar. A execução das medidas socioeducativas em meio aberto no município de Pouso Alegre, Minas Gerais. 2012. 103 f. Dissertação (Mestrado Profissional “Adolescente em Conflito Com A Lei”). - Universidade Bandeirante Anhanguera, São Paulo, 2012.

BRASIL. Lei no 8.069, de 13 de julho de 1990. Dispõe sobre o Estatuto da Criança e do Adolescente e dá outras providencias. Diário Oficial da União, Brasília, DF: Presidência da República, 1990. Disponível em: http://www.planalto.gov.br/ccivil_03/leis/18069.htm. Acesso em: 17 set. 2019.

. Lei no 12.435, de 06 de julho de 2011. Altera a Lei no 8.742, de 7 de dezembro de 1993, que dispõe sobre a organização da Assistência Social. Diário Oficial da União, Brasília, DF, 2011. Disponível em: http://www.planalto.gov.br/ccivil_03/_Ato2011-2014/2011/Lei/L12435.htm. Acesso em: 17 set. 2019.

Lei $\mathrm{n}^{\circ}$ 12.594, de 18 de janeiro de 2012. Institui o Sistema Nacional de Atendimento Socioeducativo. SINASE. Diário Oficial da União, Brasília, DF, 2012. Disponível em: http://www.planalto.gov.br/ccivil_03/_Ato2011-2014/2012/Lei/L12594.htm. Acesso em: 18 jun. 2020.

. Secretaria de Direitos Humanos. Levantamento Anual dos/as Adolescentes em Conflito com a Lei - 2012. Diário Oficial da União, Brasília: DF, 2013. Disponível em: https://www.mdh.gov.br/navegue-por-temas/crianca-e-

adolescente/Levantamento_2012VersaoFinal.pdf. Acesso em: 17 set. 2019.

. Ministério do Desenvolvimento Social. Secretaria Nacional de Assistência Social. Relatório da pesquisa nacional das medidas socioeducativas em meio aberto no sistema único de assistência social. Diário Oficial da União, Brasília, DF, 2018. Disponível em: http://www.mds.gov.br/webarquivos/publicacao/assistencia_social/relatorios/Medidas_Socioeducati vas_em_Meio_Aberto.pdf. Acesso em: 17 set. 2019.

CARDOSO, Priscila Carla. A construção de identidades de adolescentes autores de atos infracionais durante suas trajetórias escolares. 2017. 180 f. Dissertação (Mestrado em Educação). Universidade Estadual Paulista, Instituto de Biociências de Rio Claro, Rio Claro, 2017. Disponível em: https://repositorio.unesp.br/bitstream/handle/11449/152002/cardoso_pc_me_rcla.pdf?sequenc e=3\&isAllowed $=$ y. Acesso em: 17 set. 2019.

CARVALHO, Luiz Ramom Teixeira. Adolescente em conflito com a lei e políticas públicas: a socioeducação é um direito fundamental? 2018. 63 f. Dissertação (Mestrado em Direito). Universidade 
Federal do Ceará, Fortaleza, 2018. Disponível em: http://www.repositorio.ufc.br/bitstream/riufc/36988/1/2018_dis_lrtcarvalho.pdf. Acesso em: 17 set. 2019.

CONANDA. Sistema Nacional de Atendimento Socioeducativo - SINASE/Secretaria Especial dos Direitos Humanos. Brasília: DF, 2006. Disponível em: http://www.conselhodacrianca.al.gov.br/sala-deimprensa/publicacoes/sinase.pdf. Acesso em: 18 jun. 2020.

COSTA, Antonio Carlos Gomes da. Natureza e essência da ação socioeducativa. In: INALUD; ABMP; SEDH; UNFPA (org.) Justiça adolescente e ato infracional: socioeducação e responsabilização. São Paulo - SP: INALUD, 2006, pp. 449-467.

CUNHA, Liziane Giacomelli Henriques da. A socioeducação e a produção de conhecimentos na área do Serviço Social: entre a renovação e o conservadorismo. 2013. 185 f. Dissertação (Mestrado em Serviço Social). Pontifícia Universidade Católica do Rio Grande do Sul: Porto Alegre, 2013. Disponível em: http://tede2.pucrs.br/tede2/bitstream/tede/545/1/446980.pdf. Acesso em: 17 set. 2019.

CUNHA, Kelita Rejanne Machado Gonçalves; OLIVEIRA, Maria Claudia Santos Lopes de. Adolescências e judicialização da conduta juvenil. Barbarói, [s.l.], v. 2, n. 50, p.107-130, 5 jul. 2017. APESC - Associação Pro ensino em Santa Cruz do Sul. Disponível em: https://online.unisc.br/seer/index.php/barbaroi/article/view/11143/7298. Acesso em: 26 ago. 2019.

GELLI, Sue Ellen dos Santos. Potencialidades e desafios da socioeducação em um programa de execução de medidas socioeducativas em meio aberto: um estudo qualitativo. 2013. $261 \mathrm{f}$. Dissertação (Mestrado Profissional “Adolescente em Conflito com a Lei”). Universidade Bandeirante Anhanguera, São Paulo, 2013. 2 Disponível https://repositorio.pgsskroton.com.br/bitstream/123456789/3338/1/SUE\%20ELLEN\%20DOS\%20 SANTOS\%20GELLI.pdf. Acesso em: 17 set. 2019.

GUERRA, Alexandre; POCHMANN, Marcio; SILVA, Ronnie Aldrin (org.). Atlas da Exclusão social no Brasil: dez anos depois. São Paulo: Cortez, 2014.

JACQUES, Luciana Gomes de Lima. Medidas Socioeducativas em meio aberto em Guaíba: entre pressupostos e significados. 2015. 198 f. Dissertação (Mestrado em Serviço Social). Faculdade de Serviço Social, Pontifícia Universidade Católica do Rio Grande do Sul, Porto Alegre, 2015. Disponível em: http://repositorio.pucrs.br/dspace/handle/10923/7194. Acesso em: 02 mai. 2017.

KOSIK, Karel. Dialética do concreto. 5. ed. Rio de Janeiro: Paz e Terra, 1976.

MACHADO, Erica Babini Lapa do Amaral. Socioeducação: da ontologia à teleologia - uma ambiguidade teórica. Revista Eletrônica do Curso de Direito - UFSM, Santa Maria, v. 11, n.2, p.531-537, ago, 2016. Disponível em: https://periodicos.ufsm.br/revistadireito/article/view/19934/pdf. Acesso em: 17 set. 2018.

MARX, Karl. Contribuição para a crítica da economia política. 2ed. São Paulo: Expressão Popular, (1859) 2008.

MARX, Karl. O capital. 13. ed. Rio de Janeiro: Bertrand, 1989. Livro 1.vol.1

MINAYO, Maria Cecília de Souza (Org.). Pesquisa Social: teoria, método e criatividade. 28. ed. Petrópolis, RJ: Editora Vozes, 2009. 
MIRANDA, Monize Rodrigues. A Intersetorialidade entre SUAS e SINASE: elementos teóricoconceituais e manifestações no cotidiano institucional. 2018. 144 f. Dissertação (Mestrado em Política Social). Universidade Federal de Mato Grosso, Cuiabá, 2018. Disponível em: https://sucupira.capes.gov.br/sucupira/public/consultas/coleta/trabalhoConclusao/viewTrabalh oConclusao.jsf?popup=true\&id_trabalho=7056156. Acesso em: 09 mar. 2019.

MOREIRA, Etiene Pereira; MÜLLER, Edí Lurdes; CRUZ, Lilian Rodrigues da. Centro de referência especializado da assistência social: pesquisa-intervenção na rede de proteção à infância e adolescência. Barbarói, Santa Cruz do Sul, v. 36, n. 36, p.70-82, jun. 2012. Disponível em: https://online.unisc.br/seer/index.php/barbaroi/article/view/2921/2105. Acesso em: 03 set. 2019.

NETTO, José Paulo. Introdução ao estudo do método de Marx. São Paulo: Expressão Popular, 2011.

OLIVEIRA, Renata Hoeflich Damaso de. A Política de Socioeducação no Estado do Paraná e a Transição do Sistema Estadual de Atendimento Socioeducativo (2007 - 2015). 2018, 217 f. Dissertação (Mestrado em Educação). Universidade Estadual do Oeste do Paraná, Cascavel, 2018. Disponível em: http://tede.unioeste.br/bitstream/tede/3842/5/Renata_Oliveira2018.pdf. Acesso em: 17 set. 2019.

RIZZINI, Irene; SPOSATI, Aldaíza; OLIVEIRA, Antonio Carlos de. Adolescências, direitos e medidas socioeducativas em meio aberto. São Paulo: Cortez, 2019.

RANIERE, Édio. A invenção das medidas socioeducativas. 2014. 196f. Tese (Doutorado em Psicologia Social e Institucional). Universidade Federal do Rio Grande do Sul, Porto Alegre, 2014. Disponível em:

https://www.lume.ufrgs.br/bitstream/handle/10183/87585/000911217.pdf?sequenc. Acesso em: 17 set. 2019.

SAWAIA, Bader Burihan; A dialética contra a cilada negadora da práxis psicossocial - prefácio. Em: ABRANTES, Angelo Antonio; SILVA, Nilma Renildes da; MARTINS, Sueli Terezinha Ferreira (Org.). Método histórico-social na psicologia social. Petrópolis - Rio de Janeiro: Vozes, 2005, pp. 7-14.

SOUZA, Telma Apolônio de. A Rede de Proteção Integral Para os Jovens em Conflito com a Lei no Município de Cabedelo/PB. 2018. 140 f. Dissertação (Mestrado em Direitos Humanos, Cidadania e Políticas Públicas). - Universidade Federal da Paraíba - João Pessoa, 2018.

Disponível

em: https://sucupira.capes.gov.br/sucupira/public/consultas/coleta/trabalhoConclusao/viewTrabalhoCo nclusao.jsf?popup=true\&id_trabalho=7210111. Acesso em: 09 mar. 2019.

TEIXEIRA, Joana D’Arc. Dos sujeitos e lugares da punição: da passagem do/a jovem perigoso/a para o/a jovem em perigo. Um estudo das dimensões do dispositivo da gestão dos riscos e de controle social da juventude. 2015. 252 f. Tese (Doutorado em Ciências Sociais). Faculdade de Filosofia e Ciências, Universidade Estadual Paulista, - Unesp, Marília, 2015.

Disponível em: https://repositorio.unesp.br/bitstream/handle/11449/138542/000863529.pdf?sequence=1\&isAl lowed=y. Acesso em: 16 jan. 2019.

VENTURA, Tatiane Andrade. $\mathbf{O}$ atendimento às medidas socioeducativas no âmbito do Sistema Único de Assistência Social (SUAS). 2014. 115 f. Dissertação (Mestrado em Serviço Social). Faculdade 
de Serviço Social, Pontifícia Universidade Católica do Rio Grande do Sul, Porto Alegre, 2014. Disponível em: http://repositorio.pucrs.br/dspace/handle/10923/5696. Acesso em: 17 set. 2019.

Submetido: $20 / 09 / 2019$

Aprovado: 07/07/2020 